\title{
Aplicativo para auxiliar no ensino-aprendizagem dos cursos técnicos integrado
}

\author{
Dennis de Alcântara Garcia* Alessandra Martins Coelho \\ IF Sudeste MG câmpus Rio Pomba, Av. Dr. José Sebastião da Paixão s/nº \\ Bairro Lindo Vale - Rio Pomba / MG - CEP: 36180-000 \\ e-mail: dennisobelo@bol.com.br \\ e-mail: alessandra.coelho@,ifsudestemg.edu.br
}

\begin{abstract}
RESUMO
As escolas, com o passar do tempo, recebem cada vez mais os nativos digitais, ou seja, todos aqueles que têm acesso às tecnologias digitais em rede (ferramentas como internet $\mathrm{e}$ dispositivos móveis) e possuem habilidades para utilizá-las [5]. São alunos que se mostram mais conectados e familiarizados com os novos recursos, diferente dos docentes que nem sempre avançam com a tecnologia e suas aplicações e, por muitas vezes, resistem em utilizá-las, até mesmo para benefício próprio, construindo uma barreira que os impede de usá-las em seus ambientes de trabalho. Essa resistência pode gerar um mau uso das novas tecnologias por parte dos docentes, quando disponibilizadas a eles.

Com o passar dos anos, as escolas presenciam a transformação de salas de aula com o uso de tecnologias cada vez mais modernas, que podem ser inseridas no meio educacional, para aperfeiçoamento da área e agilidade na transmissão de conhecimento. Tecnologias como lousas digitais têm trazido bons resultados ao serem aplicadas em salas de aula, bem como tablets e smartphones [1], este último sendo o foco deste trabalho.

No IF Sudeste MG, câmpus Rio Pomba, projetos educacionais vêm sendo desenvolvidos para o ensino-aprendizagem de cursos técnicos integrado, como o software FRIGOTE, que visa o ensino de avicultura [3] e o KIMBLE, um software $3 D$ educacional de perguntas voltado para o ensino médio, que pode ser "alimentado" por qualquer professor [4].

Em entrevista realizada em 2013 com os docentes do ensino médio integrado do câmpus, por meio de formulário, esses, ao serem questionados se possuíam smartphones e se utilizavam de aplicativos para auxiliar no ensino-aprendizagem, $60 \%$ responderam que "sim". Desses, $45 \%$ utilizavam de aplicativos para auxiliá-los, $5 \%$ não utilizavam e $50 \%$ não opinaram. Apesar de $40 \%$ não terem tido contato com smartphones ou outro tipo de tecnologia em suas épocas escolaridades, $90 \%$ dos entrevistados concordaram com o uso de tecnologias dentro de sala de aulas, mas com certas restrições impostas pelo professor.

A dispersão e desinteresse dos alunos da primeira série do ensino técnico integrado em informática, levando ao uso incorreto e indevido da tecnologia em sala (computadores, celulares e tablets), foram constatados em respostas ao estudo realizado no câmpus com os mesmos [2]. O conceito de aplicações dessas novas tecnologias para o aperfeiçoamento do ensinoaprendizagem, como ferramenta para prender o interesse dos alunos no ensino e auxiliar o professor no compartilhamento de informação, ganha força para sua utilização na resolução desse e outros problemas na educação.

Com base nessas informações e com o objetivo de ser aplicada nas aulas de matemática dos diversos cursos técnicos integrado do câmpus, a fim de avaliar a usabilidade, agilidade e contribuição para o ensino-aprendizagem [2], foi proposta a reprodução da calculadora científica CASIO modelo fx-82MS para dispositivos móveis (figura 1), desenvolvida usando a linguagem LUA, na plataforma CORONA SDK (versão TRIAL), que dispõe da programação para iOS, Android, Kindle Fire e NOOK. O aplicativo, em sua versão atual, é capaz de realizar cálculos de funções trigonométricas: seno (e sua inversa), cosseno (e sua inversa), tangente (e sua inversa); logaritmo, $\ln$; funções hiperbólicas e respectivas inversas; funções estatísticas, como: moda, correlação, desvio padrão, $t$ de student, regressão linear, mediana, média aritmética; e outras funções, como: raiz quadrada, raiz cúbica, exponencial $(-1,2,3), P i$,
\end{abstract}


arredondamentos; assim como suas funções padrões de ligar e desligar, sinal +/-, seus dígitos de $0-9$ e toda sua parte gráfica com uma interface simples e amigável.

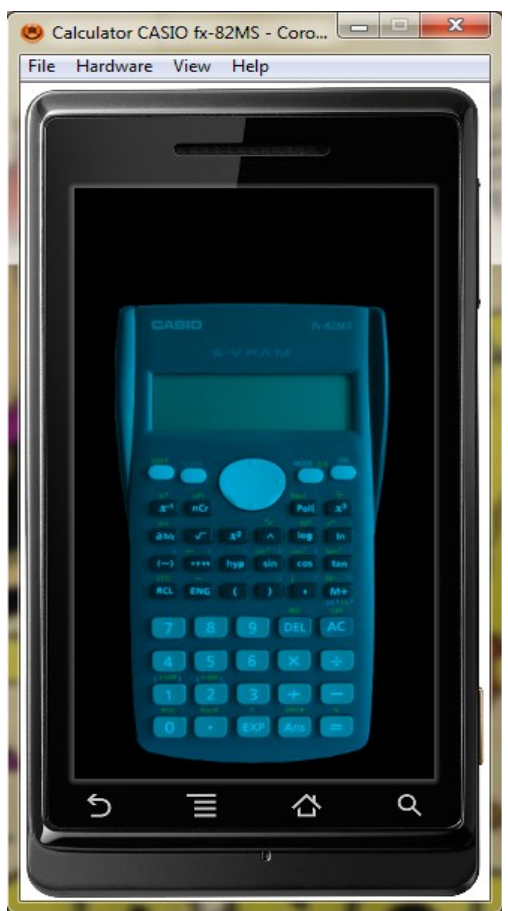

Figura 1 - Calculadora CASIO modelo fx-82MS, em desenvolvimento.

Os testes serão realizados em sala à medida que reajustes no aplicativo forem sendo feitos, a ponto de complementar e finalizar funções para obter resultados mais precisos em sua utilização.

Palavras-chave: Dispositivo móvel, Ensino-aprendizagem, Educação, Software.

Agradecimento: Os autores agradecem à FAPEMIG e ao IF SUDESTE MG pelo apoio.

\section{Referências}

[1] J. D. Carneiro. "Sem medo da tecnologia”, Revista TV Escola, p. 27-31, (2010).

[2] D. A. Garcia, W. F. Fialho e A. M. Coelho. "Uma aplicação para o ensino da matemática em cursos técnicos". XVI Encontro de Modelagem Computacional, Universidade Estadual de Santa Cruz (UESC), Ilhéus, Bahia, 2013.

[3] A. F. V. Machado, et. al. "Frigote: Uma Proposta de Ferramenta para Apoiar o Ensino de Avicultura" em Simpósio Brasileiro de Informática na Educação (SBIE), 2011.

[4] A. F. V. Machado, et. al. "Uma Proposta de Jogo Educacional 3D com Questões Didáticas" em XXII SBIE, Aracajú, SE, 2011.

[5] J. Palfrey, U. Gasser. "Born Digital: Understanding the First Generation of Digital Natives", [S.1.]: Basic Books, (2008). 